\title{
Evaluation of anatomical structures and variations in the maxilla and the mandible before dental implant treatment
}

\section{Ocena struktur anatomicznych i ich zmienności w szczęce oraz żuchwie przed leczeniem implantologicznym}

\author{
Tolga Genç $c^{1, B}$, Onurcem Duruel ${ }^{1, D}$, Hüseyin Burak Kutlu ${ }^{1, B, E}$, Erhan Dursun ${ }^{1, B, E}$, Erdem Karabulut ${ }^{2, C}$, Tolga Fikret Tözüm ${ }^{3, A, C, E, F}$ \\ ${ }^{1}$ Department of Periodontology, Faculty of Dentistry, Hacettepe University, Ankara, Turkey \\ ${ }^{2}$ Department of Biostatistics, Faculty of Medicine, Hacettepe University, Ankara, Turkey \\ ${ }^{3}$ Department of Periodontics, College of Dentistry, University of Illinois at Chicago, Chicago, United States \\ A - research concept and design; $B$ - collection and/or assembly of data; $C$ - data analysis and interpretation; \\ $D$ - writing the article; $E$ - critical revision of the article; $F$ - final approval of the article
}

Address for correspondence

Tolga F. Tözüm

E-mail: ttozum@icloud.com

Funding sources

None declared

Conflict of interest

None declared

Received on May 18, 2018

Reviewed on July 24, 2018

Accepted on August 14, 2018

DOI

$10.17219 / \mathrm{dmp} / 94303$

Copyright

() 2018 by Wroclaw Medical University

and Polish Dental Society

This is an article distributed under the terms of the

Creative Commons Attribution Non-Commercial License

(http://creativecommons.org/licenses/by-nc-nd/4.0/)

\begin{abstract}
Background. Cone beam computed tomography (CBCT) allows a detailed visualization of the anatomic structures of the jaw. There have been presented variations of the anatomic structures between genders after evaluating the structures in detail.

Objectives. The aim of this study was to investigate the anatomic variations of the jaws according to gender and age in an effort to avoid complications during implant surgeries.

Material and methods. In this retrospective study, a total of 159 scans (87 of the maxilla, 72 of the mandible) were evaluated in order to analyze the effect of age and gender on these anatomic variations.

Results. According to statistical analysis, gender affected the crestal dimensions above the mandibular canal and sinus mucosal thickening. The mean value of the width of the mandibular canal, the distance between the mandibular canal and the superior border of the mandible, the distance between the mandibular canal and the inferior border of the mandible, the diameter of the mental foramen, the distance between the mental foramen and the inferior border of the mandible, and the distance between the lingual foramen and the inferior border of the mandible were significantly greater in female patients than in male subjects $(p<0.001)$. However, sinus mucosal thickening and the diameter of the posterior superior alveolar artery (PSAA) were significantly greater in males as compared to females $(p<0.001)$. While the configuration of the nasopalatine canal was funnel-shaped in female patients, this configuration was found to be cylinder-shaped in male subjects. A high prevalence of sinus septa (43.7\%) and PSAA (87.4\%) was detected in the scans.

Conclusions. When planning dental implants, radiographic examinations, alongside clinical examinations, have become necessary to reduce the risk of implant surgery failure and complications. The CBCT imaging is a valuable tool to determine the anatomic structures before carrying out any surgeries, including implant surgery. Gender affects anatomical variations and dimensions significantly, even when they are not affected by age. Large population focused and multicenter studies may provide a better understanding of the need to evaluate the anatomical structures in detail.
\end{abstract}

Key words: dental implant, mandible, maxilla, anatomy, cone beam computed tomography

Słowa kluczowe: implant stomatologiczny, żuchwa, szzzęka, anatomia, stożkowa tomografia komputerowa 


\section{Introduction}

Edentulous patients live a life with some physical, emotional and psychological complaints, such as decreased chewing efficiency, decreased esthetic appearance and decreased self-confidence. One possible solution to this problem are teeth-supported fixed partial prostheses, overdentures and dental implant-supported prostheses. ${ }^{1}$

Dental implant placement is a routine and predictable technique, used to replace the missing teeth for esthetic, phonetic and biomechanical reasons. Sufficient bone quantity and quality are important for proper dental implant placement and for long-term satisfactory treatment outcome. ${ }^{2}$ The alveolar ridge resorption and the maxillary sinus expansion are the main limiting factors that make reconstruction of the posterior maxilla more difficult. Apart from that, compromised bone height and width, as well as localization of the mental foramen and the mandibular canal are the main disadvantageous factors in the reconstruction of the mandible. It is important to know the anatomic features in these areas when performing surgeries (e.g., dental implant, sinus lifting procedures and bone augmentation). ${ }^{3,4}$ Data about the anatomic structures and variations reduces the risk of complications, such as bleeding of the posterior superior alveolar artery (PSAA), sinus membrane perforation, neurosensory disturbance of the lower lip and chin, and lingual plate perforation. ${ }^{2,5}$

Dental implant site evaluation, oral and maxillofacial trauma, and orthodontics are some of the most frequent indications for cone beam computed tomography (CBCT). Cone beam computed tomography uses a cone or pyramid-shaped beam to obtain multiple projections in only 1 rotation. ${ }^{6}$ The CBCT images allowed us to examine more precisely the location of the anatomic structures and provided information about bone morphology and sinus pathologies, which is of great importance for dental implant planning. ${ }^{2}$ Although a few studies have examined the anatomic structures separately, ${ }^{2,7,8}$ full-mouth radiological examinations have not been reported yet. Hence, the aim of this study was to examine the anatomic structures and variations according to gender and age in order to prevent complications, using the CBCT scans.

\section{Material and methods}

A total of 159 CBCT scans (87 maxillae and 72 mandibles) from patients undergoing mandible and/or maxilla hard tissue augmentation surgeries and/or implant therapy in the Department of Periodontology at the Hacettepe University (Ankara, Turkey) were chosen for this retrospective clinical study. Only high-quality computerized images, axial sections with 1-millimeter intervals were included in the study, whereas low-quality images, such as scattering, and inferior or superior level of window exposure, were excluded. The scans were evaluated by 1 calibrated investigator (T.G.). This retrospective study was reviewed and approved by Non-Interventional Clinical Research Ethics Board of the Hacettepe University (GO 14/279 - May 9, 14, 2014).

\section{Evaluation of the maxilla via the cone beam computed tomography scans}

Fifty-four patients were female and 33 were male. The mean age was $51.9 \pm 11.4$ years. All 87 CBCT scans were evaluated for the following items bilaterally: mesiodistal and buccopalatinal dimensions of the maxillary sinus; prevalence of sinus septa $>2.5 \mathrm{~mm}$; localization of sinus septa - anterior (mesial side of first molar), middle (between mesial border of first molar and distal border of second molar) and posterior (distal side of second molar) ${ }^{9}$; thickening of the Schneiderian membrane ${ }^{10}$; height and width of the posterior alveolar ridge; diameter and location of PSAA - intraosseous (type 1), below the membrane (type 2), on the outer cortex of the lateral sinus wall (type 3$)^{2}$; diameter of the nasopalatine canal - crestal, medial, apical; length of the nasopalatine canal; and canal morphology of the nasopalatine canal - cylindrical, banana-like, hourglass-like, funnel-like. ${ }^{7}$

\section{Evaluation of the mandible via the cone beam computed tomography scans}

Forty-two patients were female and 30 were male. The mean age was $52.9 \pm 10.7$ years. All 72 CBCT scans were evaluated bilaterally. The selected landmarks were the following: vertical size of the mandibular canal; distance between the mandibular canal and the inferior border of the mandible; distance between the mandibular canal and the crest; localization of the mental foramen mesial side of first premolar, between first premolar and second premolar, distal side of second premolar; diameter of the mental foramen; distance between the mental foramen and the inferior border of the mandible; distance between the mental foramen and the crest; prevalence of the anterior alveolar loop (aAL); size of the anterior loop - anteroposterior and caudal; location of the lingual foramen; diameter of the lingual foramen; vertical distance from the mandibular border; distance between the lingual foramen and the crest; vascular type of the lingual canal - mono, bifid and triple. They were measured according to protocol. ${ }^{8,11}$

\section{Statistical analyses}

All statistical data was processed using SPSS v. 11.5 software for Windows (IBM, Chicago, USA). Using the Kolmogorov-Smirnov statistical analysis, it was determined that intermittent and continuous numeric variables did/ did not present normal distribution. The homogeneity 
of variance was tested by the Levene test. The mean and standard deviation were used for descriptive statistics in the case of intermittent and continuous numeric variables. Categorical variables were shown as the number of events and percentage.

Student's t-test was used to calculate the average of independent pairs; for more than 2 independent groups, one-way analysis of variance (ANOVA) was utilized. If one-way ANOVA results were statistically significant, the parameters causing the difference were determined by using post hoc Tukey's honest significant difference (HSD) test. Categorical variables were calculated using Pearson's $\chi^{2}$, likelihood ratio and Fischer's exact tests. The correlations between continuous and intermittent numeric variables were investigated using Pearson's correlation test. The comments and assessments were based on comparisons with a statistical significance of 0.05 .

\section{Results}

\section{Maxilla}

No statistically significant difference was detected between the mean age of 33 male and 54 female patients $(\mathrm{p}=0.202)$ (Table 1$)$. The presence of posterior teeth did not differ significantly according to gen$\operatorname{der}(p=0.396)$. Similar results were observed for the presence of sinus septa in male subjects compared with female subjects $(\mathrm{p}=0.110)$. In presenting sinus septa subjects, the location of sinus septa did not differ significantly according to gender $(\mathrm{p}=0.828)$. Sinus membrane thickening in male patients was observed more often than in female patients $(\mathrm{p}=0.008)$. However, there was no significant difference between the types of sinus membrane thickening in both genders $(\mathrm{p}=0.174)$. The presence of PSAA was not significantly different between genders $(p=0.195)$. In presenting PSAA subjects, the localization of PSAA was similar in genders $(p=0.416)$. In male subjects, the diameters of PSAA were mostly wider than $1 \mathrm{~mm}$. However, they were $1 \mathrm{~mm}$ in female subjects $(\mathrm{p}=0.035)$.

The canal morphology of the nasopalatine canal differed between genders significantly $(p=0.043)$. A cylindrical canal shape $(60.6 \%)$ was the most prevalent shape in male subjects, whereas a funnel-like shape (46.3\%) was the most prevalent in female patients. The mesiodistal and buccopalatinal dimensions of the sinus, the height and width of the posterior alveolar ridge, the diameter of the nasopalatine canal (apical), and the length of the nasopalatine canal were not significantly different in genders $(p>0.05)$. Although the diameter of the nasopalatine canal (middle: $\mathrm{p}=0.003$; crestal: $\mathrm{p}=0.009$ ) was significantly wider in male patients than in female patients, no significant correlation between age and the radiological measurements were observed $(\mathrm{p}>0.05)$.
Table 1. Demographic and clinical parameters of patients according to gender with regard to the maxilla

\begin{tabular}{|c|c|c|c|}
\hline Parameters & $\begin{array}{l}\text { Males } \\
(n=33)\end{array}$ & $\begin{array}{l}\text { Females } \\
(n=54)\end{array}$ & $\mathrm{p}$-value \\
\hline Age [years] & $53.9 \pm 10.3$ & $50.7 \pm 11.9$ & 0.202 \\
\hline $\begin{array}{l}\text { Presence/absence } \\
\text { of posterior teeth }\end{array}$ & & & 0.396 \\
\hline none & $12(36.4)$ & $15(27.8)$ & \\
\hline several & $19(57.6)$ & $31(57.4)$ & \\
\hline dentate & $2(6.1)$ & $8(14.8)$ & \\
\hline Presence of septa & $18(54.5)$ & $20(37.0)$ & 0.110 \\
\hline Localization of septa & & & 0.828 \\
\hline anterior & $1(5.6)$ & $2(10.0)$ & \\
\hline middle & $14(77.8)$ & $14(70.0)$ & \\
\hline posterior & $3(16.7)$ & $4(20.0)$ & \\
\hline Sinus membrane thickening & $31(93.9)$ & $38(70.4)$ & $0.008^{*}$ \\
\hline $\begin{array}{l}\text { Classification } \\
\text { of membrane thickening }\end{array}$ & & & 0.174 \\
\hline flat & $8(25.8)$ & $19(50.0)$ & \\
\hline hemispheric & $10(32.3)$ & $9(23.7)$ & \\
\hline mucosal-like & $7(22.6)$ & $7(18.4)$ & \\
\hline mixed & $6(19.4)$ & $3(7.9)$ & \\
\hline Visualization of PSAA & $31(93.9)$ & $45(83.3)$ & 0.195 \\
\hline Localization of PSAA & & & 0.416 \\
\hline below the membrane & $12(38.7)$ & $23(51.1)$ & \\
\hline intraosseous & $15(48.4)$ & $15(33.3)$ & \\
\hline $\begin{array}{l}\text { on the outer cortex } \\
\text { of the lateral sinus wall }\end{array}$ & $4(12.9)$ & $7(15.6)$ & \\
\hline Width of PSAA & & & $0.035^{*}$ \\
\hline$<1 \mathrm{~mm}$ & $9(29.0)$ & $21(46.7)$ & \\
\hline $1 \mathrm{~mm}$ & $9(29.0)$ & $17(37.8)$ & \\
\hline$>1 \mathrm{~mm}$ & $13(41.9)$ & 7 (15.6) & \\
\hline $\begin{array}{l}\text { Canal morphology } \\
\text { of the nasopalatine canal }\end{array}$ & & & $0.043^{*}$ \\
\hline cylindrical & $20(60.6)$ & $20(37.0)$ & \\
\hline banana-like & $1(3.0)$ & - & \\
\hline hourglass-like & $5(15.2)$ & $9(16.7)$ & \\
\hline funnel-like & $7(21.2)$ & $25(46.3)$ & \\
\hline
\end{tabular}

Data presented as mean \pm standard deviation (SD) or as number (percentage). PSAA - posterior superior alveolar artery; ${ }^{*}$ statistically significant $(p<0.05)$.

With regard to the mean value of age, male and female subjects edentulous in the posterior regions were expectedly older than dentate men and women $(p=0.019)$. The presence of sinus septa $(\mathrm{p}=0.061)$ and the location of sinus septa $(\mathrm{p}=0.946)$ did not differ significantly for the mean value of age. The mean value of age was found similar between the presence and absence of sinus membrane thickening ( $p=0.446$ ). Furthermore, there was no significant difference between the types of sinus membrane thickening for the mean value of age $(p=0.303)$. No significant difference for the mean value of age was observed between the presence and absence of PSAA ( $p=0.605)$. 
The localization of PSAA ( $\mathrm{p}=0.428$ ) and the diameter of PSAA ( $p=0.065)$ did not differ significantly for the mean value of age. The canal morphology of the nasopalatine canal did not differ significantly for the mean value of age $(\mathrm{p}=0.419)$.

The average buccopalatinal dimensions of the sinus between the groups were similar with regard to the presence of posterior teeth. The mean value of mesiodistal dimensions of the sinus was similar $(\mathrm{p}=0.713)$. There was no statistically significant difference between the groups in terms of sinus membrane thickening ( $p=0.346)$. However, the classification of membrane thickening, in the groups where sinus membrane thickening was detected, showed a statistically significant difference depending on the presence of posterior teeth $(p=0.029)$. Compared with posterior edentulous jaws, flat sinus membrane thickening was found statically significantly frequently ( $p=0.049)$, whereas semi-aspherical sinus membrane thickening was observed rarely $(\mathrm{p}=0.035)$ (Table 2).

\section{Mandible}

No statistically significant difference was detected between the mean age of 30 male and 42 female patients $(\mathrm{p}=0.317)$ (Table 3$)$. The distribution of the presence of posterior teeth did not differ significantly according to gender $(\mathrm{p}=0.798)$. The mental foramen localization in terms of gender distribution was statistically similar $(\mathrm{p}=1.000)$. There was no statistically significant difference between men and women in relation to the loop presence $(p=0.265)$. There was no statistically significant gender difference in terms of the presence of the lingual foramen groups $(\mathrm{p}=0.643)$. The lingual foramen localizations, in the cases determined by the distribution of men and women, were statistically similar $(p=0.679)$. There was no statistically significant difference in terms of the lingual canal branching between genders $(p=0.606)$. The distribution of the lingual foramen width was statistically similar between men and women $(\mathrm{p}=0.701)$.
Table 3. Demographic and clinical parameters of patients according to gender with regard to the mandible

\begin{tabular}{|c|c|c|c|}
\hline Parameters & $\begin{array}{l}\text { Males } \\
(n=30)\end{array}$ & $\begin{array}{l}\text { Females } \\
(n=42)\end{array}$ & $\mathrm{p}$-value \\
\hline Age [years] & $54.4 \pm 9.5$ & $51.8 \pm 11.5$ & 0.317 \\
\hline $\begin{array}{l}\text { Presence/absence } \\
\text { of posterior teeth }\end{array}$ & & & 0.798 \\
\hline none & $11(36.7)$ & $13(31.0)$ & \\
\hline several & $17(56.7)$ & $27(64.3)$ & \\
\hline dentate & $2(6.7)$ & $2(4.8)$ & \\
\hline $\begin{array}{l}\text { Localization } \\
\text { of the mental foremen }\end{array}$ & & & 1.000 \\
\hline $\begin{array}{l}\text { between first premolar } \\
\text { and second premolar }\end{array}$ & $26(86.7)$ & $36(85.7)$ & \\
\hline distal side of second premolar & $4(13.3)$ & $6(14.3)$ & \\
\hline Prevalence of aAL & $5(16.7)$ & $3(7.1)$ & 0.265 \\
\hline Visualization of the lingual foramen & $27(90.0)$ & $40(95.2)$ & 0.643 \\
\hline Localization of the lingual foramen & & & 0.679 \\
\hline middle & $24(88.9)$ & $37(92.5)$ & \\
\hline lateral sides & $3(11.1)$ & $3(7.5)$ & \\
\hline Vascular type of the lingual canal & & & 0.606 \\
\hline mono & $14(51.9)$ & $21(52.5)$ & \\
\hline bifid & $9(33.3)$ & $16(40.0)$ & \\
\hline triple & $4(14.8)$ & $3(7.5)$ & \\
\hline Diameter of the lingual foramen & & & 0.701 \\
\hline$<1 \mathrm{~mm}$ & $17(63.0)$ & $27(67.5)$ & \\
\hline$\geq 1 \mathrm{~mm}$ & $10(37.0)$ & $13(32.5)$ & \\
\hline
\end{tabular}

Data presented as mean \pm standard deviation (SD) or as number (percentage). PSAA - posterior superior alveolar artery; aAL - anterior alveolar loop; * statistically significant $(p<0.05)$.

The mean value of the width of the mandibular canal, the distance between the mandibular canal and the crest, the distance between the mandibular canal and the inferior border of the mandible, the diameter of the mental foramen, the distance between the mental foramen and the inferior border of the mandible, and the distance between the lingual foramen and the inferior border of the mandible measurements were significantly higher in male

Table 2. Clinical measurements of cases according to gender with regard to the maxilla

\begin{tabular}{|c|c|c|c|c|c|c|c|}
\hline \multirow{2}{*}{ Clinical measurements } & \multicolumn{3}{|c|}{ Males } & \multicolumn{3}{|c|}{ Females } & \multirow{2}{*}{$p$-value } \\
\hline & $\mathrm{n}$ & mean & SD & $\mathrm{n}$ & mean & SD & \\
\hline Buccopalatinal dimensions of the sinus [mm] & 33 & 12.51 & 2.12 & 54 & 12.69 & 1.90 & 0.671 \\
\hline Mesiodistal dimensions of the sinus [mm] & 33 & 18.02 & 2.87 & 54 & 17.55 & 2.52 & 0.427 \\
\hline Height of the posterior alveolar ridge [mm] & 33 & 8.02 & 3.31 & 54 & 9.61 & 3.84 & 0.051 \\
\hline Width of the posterior alveolar ridge [mm] & 33 & 7.76 & 2.22 & 54 & 7.51 & 1.97 & 0.588 \\
\hline Diameter of the nasopalatine canal (apical) [mm] & 33 & 2.53 & 1.19 & 54 & 1.86 & 1.11 & $0.009^{*}$ \\
\hline Diameter of the nasopalatine canal (middle) [mm] & 33 & 2.27 & 1.03 & 54 & 1.64 & 0.86 & $0.003^{*}$ \\
\hline Diameter of the nasopalatine canal (crestal) [mm] & 33 & 3.23 & 1.04 & 54 & 3.51 & 1.61 & 0.372 \\
\hline Length of the nasopalatine canal [mm] & 33 & 11.35 & 2.96 & 54 & 10.83 & 2.22 & 0.358 \\
\hline
\end{tabular}

SD - standard deviation; * statistically significant $(p<0.05)$. 
subjects than in females $(\mathrm{p}<0.05)$. However, the distance between the mental foramen and the crest, and the mean value of the distance between the lingual foramen and the inferior border of the mandible were statistically similar ( $p>0.05)$. Statistical comparisons of the anteroposterior and caudal length of the loop could not be made due to an insufficient number of evaluations. There was no statistically significant correlation between age and all the clinical measurements in all cases $(\mathrm{p}>0.05)$. The mean age of patients edentulous in the posterior region was higher than in the case of dentate patients. Hence, the presence of posterior teeth in relation to age indicates significant differences $(p=0.012)$. There was no statistically significant difference in the mean age in relation to the mental foramen localization ( $p=0.208)$. No statistical difference was observed between the mean age of subgroups depending on the presence/absence of aAL ( $p=0.796)$.

The difference between the mean age of subjects based on the visualized/non-visualized lingual foramen was not significant $(\mathrm{p}=0.678)$. In subjects presenting the lingual foramen, there was no statistically significant difference between the groups in terms of the lingual foramen localization ( $p=0.790)$. There was no statistically significant difference in terms of the lingual canal branching with regard to the mean age of groups $(p=0.927)$. The width of the lingual foramen did not differ significantly for the mean value of age $(\mathrm{p}=0.400)$. The mean value of distance between the lingual foramen and the crest of dentate patients was significantly greater than in edentulous patients $(\mathrm{p}<0.001)$. According to the presence of posterior teeth, the mean value of the distance between the lingual foramen and the inferior border of the mandible was statistically similar $(\mathrm{p}=0.388)$ (Table 4$)$.

\section{Discussion}

Having knowledge about the anatomic features in surgical areas while performing surgeries is important for treatment success. ${ }^{3,4}$ Data about the anatomic structures and variations reduces the risk of such complications as neurosensory disturbance, lingual plate perforation, etc. ${ }^{2,5}$ Cone beam computed tomography is preferred for dental implant site evaluation. ${ }^{12}$ Cone beam computed tomography uses a cone or pyramid-shaped beam to obtain multiple projections in only a single $360^{\circ}$ rotation. In this study, the CBCT scans from the upper and lower jaws were examined. Using all the data and calculated rates of anatomic variations, comparisons based on gender and correlation analysis between age and the measurements were performed. For maxillary evaluation studies, the percentage of membrane thickening was $79.3 \%$ and membrane thickening in men had a significantly higher incidence than in females. There was no significant correlation between membrane thickening and age. Membrane thickening was most often classified as a flat-shaped thickening (39.1\%), and when membrane thickening was evaluated in terms of gender classification, there was no significant difference between the groups. Schneider et al. reported that the membrane thickening ratio was $64.49 \%$ and flat-shaped thickening was observed in $45.65 \%$ of the subjects. ${ }^{13}$ In the same study, there was no significant correlation between membrane thickening and age, and it was reported that the presence of membrane thickening was greater in male subjects. ${ }^{13}$ Bornstein et al. reported that the presence of teeth with apical sinus pathology increases the presence of membrane thickening and the risk of sinusitis. ${ }^{14}$ In our study, membrane thickening rates in both genders were similar to those reported in the literature. Furthermore, the ratio of detecting membrane thickening in male subjects was higher than in females.

The presence of sinus septa in this study was calculated at $43.7 \%$ in all subjects, and sinus septa in the central region (between distal sides of second premolar and second molar) was observed in $73.7 \%$ of patients. No relation was found between the presence of sinus septa and gender and/or age. Underwood reported that the presence and location of sinus septa were most often observed (66.7\%) in the posterior region (distal side of tooth number 7 ). ${ }^{15}$ Kim et al. stated that the presence of sinus septa was reported in $38 \%$ of the patients and the location of septa was most often observed in the central region. ${ }^{16}$ The

Table 4. Clinical measurements of cases according to gender with regard to the mandible

\begin{tabular}{|c|c|c|c|c|c|c|c|}
\hline \multirow{2}{*}{ Clinical measurements } & \multicolumn{3}{|c|}{ Males } & \multicolumn{3}{|c|}{ Females } & \multirow{2}{*}{$\mathrm{p}$-value } \\
\hline & $\mathrm{n}$ & mean & SD & $\mathrm{n}$ & mean & SD & \\
\hline Vertical size of the mandibular canal [mm] & 30 & 2.71 & 0.52 & 42 & 2.34 & 0.50 & $0.003^{*}$ \\
\hline Distance between the mandibular canal and the crest [mm] & 30 & 12.46 & 3.17 & 42 & 10.69 & 3.67 & $0.037^{*}$ \\
\hline Distance between the mandibular canal and the inferior border of the mandible [mm] & 30 & 8.05 & 1.51 & 42 & 7.11 & 1.14 & $0.004^{*}$ \\
\hline Diameter of the mental foramen [mm] & 30 & 3.27 & 0.78 & 42 & 2.87 & 0.64 & $0.022^{*}$ \\
\hline Distance between the mental foramen and the crest [mm] & 30 & 9.85 & 3.08 & 42 & 8.60 & 3.43 & 0.117 \\
\hline Distance between the mental foramen and the inferior border of mandible [mm] & 30 & 12.13 & 2.01 & 42 & 10.87 & 1.71 & $0.005^{*}$ \\
\hline Distance between the lingual foramen and the crest [mm] & 27 & 14.70 & 4.81 & 40 & 12.54 & 3.89 & $0.046^{*}$ \\
\hline Distance between the lingual foramen and the mandibular border [mm] & 27 & 12.31 & 3.37 & 40 & 10.93 & 3.44 & 0.106 \\
\hline
\end{tabular}

SD - standard deviation; * statistically significant $(p<0.05)$ 
literature about the presence and localization of sinus septa presents various results. The presence of septa has not been associated with age and gender, as in our study. Although the relation between the status of dentation and septa prevalence was not evaluated in the present study, the literature reveals that the presence of sinus septa is detected more frequently in totally edentulous subjects rather than in dentate subjects. ${ }^{9}$

The presence of PSAA was found in $87.4 \%$ of subjects. The posterior superior alveolar artery was often observed in the inner surface of the lateral wall of the sinus (46.1\%). In addition, the width of PSAA was $<1 \mathrm{~mm}$ with a ratio of $39.5 \%$. Age and gender did not have a significant effect on the PSAA presence. The width of PSAA was greater in male subjects than in females. Güncü et al. reported that the visualization of PSAA was $64.5 \%$ in 242 CBCT scans ${ }^{2}$; however, Mardinger et al. reported $55 \% .{ }^{17}$ The latter authors reported a significant positive correlation between age and the width of PSAA, and found no relation between gender and the width of PSAA. ${ }^{17}$ Güncü et al. noted that age did not have a significant effect on the visualization of PSAA and reported that there was a positive correlation between age and the PSAA width. ${ }^{2}$

A cylindrical canal shape was often observed in the present study (46\%). A cylindrical canal shape was the most prevalent in male patients (60.6\%), whereas a funnel-like canal was identified mostly in females (46.3\%). No correlation between age and the shape of the nasopalatine canal was found. The mean value of the length of the nasopalatine canal was $11.03 \pm 2.52 \mathrm{~mm}$. It was concluded that age and gender had no effect on the length of the nasopalatine canal. The mean values of the diameter of the nasopalatine canal were $2.11 \pm 1.18 \mathrm{~mm}$ (apical), $1.88 \pm 0.97 \mathrm{~mm}$ (middle) and $3.4 \pm 1.42 \mathrm{~mm}$ (crestal). There was no correlation between age and the diameter of the nasopalatine canal, whereas it was noted that gender affects the diameter of the nasopalatine canal. The diameter of the nasopalatine canal was greater in male subjects than in females in apical and middle regions. Tözüm et al. reported that a cylindrical canal shape was the most prevalent canal morphology in both genders. $^{7}$ Bornstein et al. determined the mean value of the length of the nasopalatine canal as $10.99 \mathrm{~mm},{ }^{18}$ whereas Tözüm et al. noted $10.86 \mathrm{~mm} .{ }^{7}$ These results are similar to those of our study. They also measured the mean value of the apical region of the nasopalatine canal as $2.76 \pm 1.4 \mathrm{~mm}$ and the mean value of the crestal region of the nasopalatine canal was $2.93 \pm 1.01 \mathrm{~mm}$. However, they reported that age and gender had no effect on these measurements, which is in line with the present study. According to these papers, the anatomic structures should be measured carefully by using the CBCT scans when planning implant surgery. ${ }^{7}$

The height of the residual alveolar ridge of the posterior maxilla is important for implant planning and advanced surgery (internal sinus lifting or lateral approach technique). In this study, measurements were taken from the first premolar and the first and second molar regions, respectively. The average of these measurements was $9.01 \pm 3.71 \mathrm{~mm}$. There was no difference between male and female subjects. Shanbhag et al. calculated the average value of the height of the residual alveolar ridge of the posterior maxilla as $6.39 \pm 3.52 \mathrm{~mm}$. A negative correlation was found between age and the height of the residual alveolar ridge, in accordance with the results of our study. ${ }^{19}$

In the present study, the localization of the mental foramen was observed between the first and second premolar regions in $86.1 \%$. Age and gender did not affect the localization of the mental foramen as expected. Von Arx et al. and Kalender et al. found that the localization of the mental foramen between the first and second premolar region was higher than in other regions, i.e., $56 \%$ and $59.8 \%$, respectively. ${ }^{11,20}$ Kalender et al. reported that gender did not have any effect on the localization of the mental foramen, which is in line with the results of the present study. ${ }^{20}$ In this study, the average diameter of the mental foramen was $3.04 \pm 0.73 \mathrm{~mm}$ and was significantly greater in male than in female subjects. Von Arx et al. and Kalender et al. measured the mean value of the diameter of the mental foramen with the results of 3.1 and $3.55 \mathrm{~mm}$, respectively. ${ }^{11,20}$ They both reported that the diameter of the mental foramen was greater in males than in females, which is in line with the results of the present study. ${ }^{11,20}$ The mean values of the distance between the mental foramen and the inferior border of the mandible, and the distance between the mental foramen and the crest were $11.4 \pm 1.93 \mathrm{~mm}$ and $9.12 \pm 3.32 \mathrm{~mm}$, respectively. No correlation was found between these measurements and age. The distance between the mental foramen and the inferior border of the mandible was smaller in female subjects than in male subjects. Haktanır et al. reported that gender was not correlated with the distance between the mental foramen and the inferior border of the mandible. ${ }^{21}$ However, Kalender et al. reported that gender had an effect on the distance between the mental foramen and the inferior border of the mandible, which is in line with the results of this study. ${ }^{20}$

The presence of aAL was $11.1 \%$ in this study. Age and gender did not affect the presence of aAL. The anterior length and caudal height of aAL were $5.34 \pm 1.13 \mathrm{~mm}$ and $7.16 \pm 4.11 \mathrm{~mm}$, respectively. In the literature, various data about the presence of aAL has been found. In cadaver studies, the presence of aAL was found to be between 0 and $88 \%{ }^{22}$ In the CT scans, the presence of aAL was found to be $7-83 \%,{ }^{23,24}$ although the presence of aAL was determined to be $48-84 \%$ in the CBCT scans. $^{24,25}$ In the literature, the results of papers on the aAL size have shown variability. The size of aAL was $1.5-5 \mathrm{~mm}$ in cadaver studies. ${ }^{26}$ In addition, the size of aAL was $2.09-5.3 \mathrm{~mm}$ in the CT scans and the maximum size of aAL was determined as $5.7 \mathrm{~mm} \cdot{ }^{27}$ In the CBCT scans, the size of aAL was between $0.89 \mathrm{~mm}$ and 
$3.54 \mathrm{~mm}$, and the maximum size of aAL was $5.7 \mathrm{~mm} .{ }^{11}$ These various measurements in the literature might be the result of different measurement techniques and different reference points; therefore, the results of the present study must be evaluated accurately.

In the present study, the lingual foramen was detected in $93.1 \%$ of the CBCT scans. The most prevalent vascular type of the lingual canal was monovascular, in $52.2 \%$ of the cases. The mean value of the distance between the lingual foramen and the crest was $13.41 \pm 4.38 \mathrm{~mm}$. Yildırım et al. measured the distance between the lingual foramen and the crest, and their result was different from that of the present study. ${ }^{8}$ This might be the result of different measurement techniques and anatomic variations of the population. Detecting the lingual canal by using 3-dimensional (3D) imaging techniques should be essential during implant planning. In this study, the diameter of the lingual foramen classified 2 groups as $\leq 1 \mathrm{~mm}$ and $>1 \mathrm{~mm}$. The diameter of the lingual foramen $\leq 1 \mathrm{~mm}$ was found in $65.7 \%$ of subjects. Age and gender did not have an effect on the diameter of the lingual foramen. Yildırım et al. reported that the diameter of the lingual foreman $\leq 1 \mathrm{~mm}$ was found in $75.6 \%$ of the patients. ${ }^{8}$

In the present study, the mean value of the vertical size of the mandibular canal was $2.49 \pm 0.54 \mathrm{~mm}$. The average distance between the mandibular canal and the crest was $11.43 \pm 3.55 \mathrm{~mm}$. The mean value of the distance between the mandibular canal and the inferior border of the mandible was $7.5 \pm 1.38 \mathrm{~mm}$. These measurements were greater in male subjects than in females. In dentate subjects, the distance between the mandibular canal and the crest was greater than in edentulous subjects.

Hsu et al. found that the mean value of the vertical size of the mandibular canal was $2.16 \pm 0.44 \mathrm{~mm},{ }^{26}$ whereas Al-Siweedi et al. calculated it as $2.27 \pm 0.39 \mathrm{~mm},{ }^{28}$ Levine et al. reported that the average distance between the mandibular canal and the crest was $13.18 \mathrm{~mm} \pm 3.7 .{ }^{29}$ Kilic et al. reported that the mean value of the distance between the mandibular canal and the inferior border of the mandible was $10.09 \pm 3.69 \mathrm{~mm} .^{30}$ These various results might be explained by different measurement techniques and different reference points. 3-dimensional imaging techniques should be preferred to reduce the risk of complications, such as neurosensory disturbance, before implant surgeries are carried out in the posterior mandible region.

\section{Conclusions}

When planning dental implants, carrying out radiographic examinations, alongside clinical examinations, has become necessary to reduce the risk of implant surgery failure and complications. The CBCT imaging is a valuable tool to determine the anatomic structures before any surgery, including implant surgery. Gender affects anatomical variations and dimensions significantly, although they are not affected by age. Dimensions of the anatomic structures (i.e., diameter of PSAA, diameter of the nasopalatine canal, dimensions of the mandibular) were found to be greater in male subjects. In addition, a cylindrical canal shape is most frequently found in male subjects, whereas females tend to have a funnel-like shape. Large population focused and multicenter studies may provide a better understanding of the need to evaluate the anatomical structures in detail.

\section{References}

1. Asawa N, Bulbule N, Kakade D, Shah R. Angulated implants: An alternative to bone augmentation and sinus lift procedure: Systematic review. J Clin Diagn Res. 2015;9(3):ZE10-13.

2. GüncüGN,YıldırımYD,WangHL,TözümTF.Location of posteriorsuperior alveolar artery and evaluation of maxillary sinus anatomy with computerized tomography: A clinical study. Clin Oral Implants Res. 2011;22(10):1164-1167.

3. Jensen OT, Shulman LB, Block MS, lacono VJ. Report of the sinus consensus conference of 1996. Int J Oral Maxillofac Implants. 1998;13(Suppl):11-45.

4. Leite GM, Lana JP, de Carvalho Machado V, Manzi FR, Souza PE, Horta MC. Anatomic variations and lesions of the mandibular canal detected by cone beam computed tomography. Surg Radiol Anat. 2014;36(8):795-804.

5. Misch C, Crawford E. Predictable mandibular nerve location: A clinical zone of safety. Int J Oral Implantol. 1990;7(1):37-40.

6. Koong B. Cone beam imaging: Is this the ultimate imaging modality? Clin Oral Implants Res. 2010;21(11):1201-1208.

7. Tözüm TF, Güncü GN, Yıldırım YD, et al. Evaluation of maxillary incisive canal characteristics related to dental implant treatment with computerized tomography: A clinical multicenter study. J Periodontol. 2012;83(3):337-343.

8. Yıldırım YD, Güncü GN, Galindo-Moreno P, et al. Evaluation of mandibular lingual foramina related to dental implant treatment with computerized tomography: A multicenter clinical study. Implant Dent. 2014;23(1):57-63.

9. Krennmair G, Ulm CW, Lugmayr H, Solar P. The incidence, location, and height of maxillary sinus septa in the edentulous and dentate maxilla. J Oral Maxillofac Surg. 1999;57(6):667-672.

10. Soikkonen K, Ainamo A. Radiographic maxillary sinus findings in the elderly. Oral Surg Oral Med Oral Pathol Oral Radiol Endod. 1995;80(4):487-491.

11. Von Arx T, Friedli M, Sendi P, Lozanoff S, Bornstein MM. Location and dimensions of the mental foramen: A radiographic analysis by using cone-beam computed tomography. J Endod. 2013;39(12):1522-1528.

12. Ritter L, Lutz J, Neugebauer J, et al. Prevalence of pathologic findings in the maxillary sinus in cone-beam computerized tomography. Oral Surg Oral Med Oral Pathol Oral Radiol Endod. 2011;111(5):634-640.

13. Schneider AC, Bragger U, Sendi P, Caversaccio MD, Buser D, Bornstein MM. Characteristics and dimensions of the sinus membrane in patients referred for single-implant treatment in the posterior maxilla: A cone beam computed tomographic analysis. Int J Oral Maxillofac Implants. 2013;28(2):587-596.

14. Bornstein MM, Wasmer J, Sendi P, Janner SFM, Buser D, von Arx T. Characteristics and dimensions of the Schneiderian membrane and apical bone in maxillary molars referred for apical surgery: A comparative radiographic analysis using limited cone beam computed tomography. J Endod. 2012;38(1):51-57.

15. Underwood AS. An inquiry into the anatomy and pathology of the maxillary sinus. J Anat Physiol. 1910;44(Pt 4):354-369.

16. Kim MJ, Jung UW, Kim CS, et al. Maxillary sinus septa: Prevalence, height, location, and morphology. A reformatted computed tomography scan analysis. J Periodontol. 2006;77:903-908.

17. Mardinger O, Abba M, Hirshberg A, Schwartz-Arad D. Prevalence, diameter and course of the maxillary intraosseous vascular canal with relation to sinus augmentation procedure: A radiographic study. Int J Oral Maxillofac Surg. 2007;36:735-738. 
18. Bornstein MM, Balsiger R, Sendi $\mathrm{P}$, von Arx T. Morphology of the nasopalatine canal and dental implant surgery: A radiographic analysis of 100 consecutive patients using limited cone-beam computed tomography. Clin Oral Implants Res. 2011;22:295-301.

19. Shanbhag S, Karnik P, Shirke P, Shanbhag V. Cone-beam computed tomographic analysis of sinus membrane thickness, ostium paten$\mathrm{cy}$, and residual ridge heights in the posterior maxilla: Implications for sinus floor elevation. Clin Oral Implants Res. 2014;25:755-760.

20. Kalender A, Orhan K, Aksoy U. Evaluation of the mental foramen and accessory mental foramen in Turkish patients using conebeam computed tomography images reconstructed from a volumetric rendering program. Clin Anat. 2012;25(5):584-592.

21. Haktanır A, Ilgaz K, Turhan-Haktanır N. Evaluation of mental foramina in adult living crania with MDCT. Surg Radiol Anat. 2010;32(4):351-356.

22. Neiva RF, Gapski R, Wang HL. Morphometric analysis of implant-related anatomy in Caucasian skulls. J Periodontol. 2004;75(8):1061-1067.

23. Li X, Jin ZK, Zhao H, Yang K, Duan JM, Wang WJ. The prevalence, length and position of the anterior loop of the inferior alveolar nerve in Chinese, assessed by spiral computed tomography. Surg Radiol Anat. 2013;35(9):823-830.

24. Jacobs R, Mraiwa N, vanSteenberghe D, Gijbels F, Quirynen M. Appearance, location, course, and morphology of the mandibular incisive canal: An assessment on spiral CT scan. Dentomaxillofac Radiol. 2002;31(5):322-327.

25. Parnia F, Moslehifard E, Hafezeqoran A, Mahboub F, Mojaver-Kahnamoui $\mathrm{H}$. Characteristics of anatomical landmarks in the mandibular interforaminal region: A cone-beam computed tomography study. Med Oral Patol Oral Cir Bucal. 2012;17(3):e420-425.

26. Hsu JT, Huang HL, Fuh LJ, et al. Location of the mandibular canal and thickness of the occlusal cortical bone at dental implant sites in the lower second premolar and first molar. Comput Math Methods Med. 2013;2013:608570.

27. Apostolakis $D$, Brown JE. The anterior loop of the inferior alveolar nerve: Prevalence, measurement of its length and a recommendation for interforaminal implant installation based on cone beam CT imaging. Clin Oral Implants Res. 2012;23(9):1022-1030.

28. Al-Siweedi SY, Nambiar P, Shanmuhasuntharam P, Ngeow WC Gaining surgical access for repositioning the inferior alveolar neurovascular bundle. Sci World J. 2014:2014:719243.

29. Levine MH, Goddard AL, Dodson TB. Inferior alveolar nerve canal position: A clinical and radiographic study. J Oral Maxillofac Surg. 2007;65(3):470-474.

30. Kilic C, Kamburoglu K, Ozen T, et al. The position of the mandibular canal and histologic feature of the inferior alveolar nerve. Clin Anat. 2010;23(1):34-42 